\title{
Contribution of Ash Content Related to Methane Adsorption Behaviors of Bituminous Coals
}

\author{
Yanyan Feng, Wen Yang, and Wei Chu \\ Department of Chemical Engineering, Sichuan University, Chengdu 610065, China \\ Correspondence should be addressed to Wei Chu; chu1965chengdu@163.com
}

Received 10 January 2014; Revised 9 April 2014; Accepted 23 April 2014; Published 19 May 2014

Academic Editor: Jerzy Bałdyga

Copyright (C) 2014 Yanyan Feng et al. This is an open access article distributed under the Creative Commons Attribution License, which permits unrestricted use, distribution, and reproduction in any medium, provided the original work is properly cited.

\begin{abstract}
Methane adsorption isotherms on coals with varying ash contents were investigated. The textural properties were characterized by $\mathrm{N}_{2}$ adsorption/desorption isotherm at $77 \mathrm{~K}$, and methane adsorption characteristics were measured at pressures up to $4.0 \mathrm{MPa}$ at $298 \mathrm{~K}, 313 \mathrm{~K}$, and $328 \mathrm{~K}$, respectively. The Dubinin-Astakhov model and the Polanyi potential theory were employed to fit the experimental data. As a result, ash content correlated strongly to methane adsorption capacity. Over the ash range studied, $9.35 \%$ to $21.24 \%$, the average increase in methane adsorption capacity was $0.021 \mathrm{mmol} / \mathrm{g}$ for each $1.0 \%$ rise in ash content. With the increasing ash content range of $21.24 \% \sim 43.47 \%$, a reduction in the maximum adsorption capacities of coals was observed. In addition, there was a positive correlation between the saturated adsorption capacity and the specific surface area and micropore volume of samples. Further, this study presented the heat of adsorption, the isosteric heat of adsorption, and the adsorbed phase specific heat capacity for methane adsorption on various coals. Employing the proposed thermodynamic approaches, the thermodynamic maps of the adsorption processes of coalbed methane were conducive to the understanding of the coal and gas simultaneous extraction.
\end{abstract}

\section{Introduction}

Coalbed methane (CBM) as an unconventional energy resource has led to economic assessment in many countries [1-3]. However, the CBM industry still lacks an adequate understanding of the parameters determining methane production. Understanding of methane adsorption on coal is extremely significant in estimating CBM resource exploitation, and the methane-holding capacity of coal seams has become an important area of research [4-6].

The nature of coal is an important variable to be considered in the coal seam. Coal is a complex polymeric material with complicated porous structures. Most coal pores are less than $100 \mathrm{~nm}$ in diameter, making them favorable for gas adsorption but unfavorable for gas permeability. Gases in coal, mostly in adsorbed state within the micropores $(<10 \mathrm{~nm})$ [7], are primarily composed of $\mathrm{CH}_{4}(98 \%), \mathrm{CO}_{2}$, trace amount of hydrocarbons, and other gases $[7,8]$.

To date, various researchers have identified the most important factors influencing methane storage, including coal type $[9,10]$, rank $[9,11]$, moisture content $[12-14]$, temperature $[4,15]$, burial depth $[6,16]$, pore characteristics
$[3,7,17-19]$ and so on $[3,20-22]$. Ash content is often considered to be the main parameter affecting methane adsorption capacity. Ash, expressed as mineral matter [22], takes two forms in coal: inherent and extraneous mineral matter. Ash infilling predominantly clays and carbonates have been found to block the coal pore system, including cleats and fractures, and significantly reduce gas production. Additionally, much of the ash is primarily detrital constituents deposited with the organisms in coals which would not cause blockages of transport pores. It is generally considered that there is a low ash content in coals, with the coal formed combined with a large number of the organisms. With the initial increase of ash content of coal, its micropores and micropore volume would increase, while the mesopore and macropore volumes would dramatically decline. A relationship of decreasing capacity to increasing ash content has been established. However, other studies suggest that the relationship with ash content is a second-order polynomial trend with a maximum occurring.

Therefore, to address this concern, methane adsorption isotherms of coals with varying ash contents were investigated in this study, and effect of ash content on methane adsorption capacity was also studied. The texture of coals was 
determined by $\mathrm{N}_{2}$ adsorption/desorption at $77 \mathrm{~K}$. Methane adsorption was measured by a volumetric method and the Dubinin-Astakhov (D-A) model and the Polanyi potential theory were fitted to the equilibrium data. This study also presented the heat of adsorption, the isosteric heat of adsorption, and the adsorbed phase specific heat capacity for methane adsorption on the coals.

\section{Experimental}

2.1. Sample Preparation. The bituminous coals, collected from Pangpangta Colliery in Shanxi province (China), were selected as the samples. The coal samples were crushed to particles with size fraction of $40 \sim 60$ mesh, subsequently dried in an oven overnight at $110^{\circ} \mathrm{C}$, and stored in a sealed plastic container. Proximate analyses for the coals were given in Table 1. The coals contained significant amounts of fixed carbon and variable amounts of ash, and the samples with varying ash contents were considered in the evaluation of ash content effects on methane adsorption.

2.2. Characterization. The textural characterization of the samples was obtained by $\mathrm{N}_{2}$ adsorption/desorption isotherms, determined at $77 \mathrm{~K}$ with a NOVA1000e surface area and pore size analyzer (Quantachrome Company). Samples were degassed at $383 \mathrm{~K}$ for $24 \mathrm{~h}$ prior to analysis. Specific surface area (SSA) of the samples was measured from the Brunauer-Emmett-Teller (BET) method, and the mean pore size and the micropore volume were determined by nonlocal density functional theory (NLDFT) method. The total pore volume was evaluated at $p / p_{0}=0.98 \sim 0.99$, and the pore size distributions were obtained by density functional theory (DFT) equation $[3,23]$.

Proximate analysis was performed on a GF-A6 automatic proximate analyzer (Hebi Celestica Instruments Co., Ltd). All the samples were evaluated on a dry basis $[3,23]$.

2.3. Methane Adsorption. Methane adsorption measurements were performed using a volumetric method similar to that previously described $[2,3,6,23]$. The purities of $\mathrm{He}$ and methane were $99.999 \%$ and $99.99 \%$, respectively. Approximately $5 \mathrm{~g}$ of $40 \sim 60$ mesh coal was dried at $110^{\circ} \mathrm{C}$ and evacuated for $3 \mathrm{~h}$, prior to determination of void volume in the adsorption setup by helium calibration. Subsequent to helium calibration, samples were again evacuated for $3 \mathrm{~h}$ for methane adsorption. Methane was introduced into the adsorption setup to produce an adsorption isotherm under pressures up to $4.0 \mathrm{MPa}$ in the temperature range $25 \sim 55^{\circ} \mathrm{C}$. The test was repeated three times and the mean value of the equilibrium data was used to calculate the adsorption isotherm to ensure the validity of the experiment.

2.4. Modeling Methane Sorption Data. As the methane adsorption proceeds, the difference between excess adsorption amount $\left(W_{\text {excess }}\right.$, in $\mathrm{mmol} / \mathrm{g}$ ) and the absolute adsorption amount $\left(W_{\text {absolute }}\right.$, in $\left.\mathrm{mmol} / \mathrm{g}\right)$ becomes more obvious with the adsorption pressure becoming higher [3, 23, 24]. Since
TABLE 1: Proximate composition analysis of selected coal samples (mass fraction, \%).

\begin{tabular}{lcccc}
\hline Sample & $\begin{array}{c}\text { Ash } \\
\text { (dry basis) }\end{array}$ & $\begin{array}{c}\text { Fixed carbon } \\
\text { (dry basis) }\end{array}$ & $\begin{array}{c}\text { Volatile } \\
\text { matter } \\
\text { (dry basis) }\end{array}$ & Moisture \\
\hline A1 & 9.35 & 67.18 & 23.47 & 1.08 \\
A2 & 11.89 & 66.24 & 21.87 & 1.19 \\
A3 & 15.27 & 63.97 & 20.76 & 1.03 \\
A4 & 21.24 & 57.85 & 20.91 & 1.03 \\
A5 & 26.82 & 52.82 & 20.36 & 1.18 \\
A6 & 30.04 & 51.10 & 18.86 & 1.16 \\
A7 & 35.62 & 46.01 & 18.37 & 1.20 \\
A8 & 43.57 & 39.38 & 17.05 & 1.36 \\
\hline
\end{tabular}

$W_{\text {absolute }}$ cannot be directly measured, $W_{\text {excess }}$ measured from the experiments is used for the calculation of $W_{\text {absolute }}$ :

$$
W_{\text {absolute }}=\frac{W_{\text {excess }}}{1-\rho_{\text {gas }} / \rho_{a}},
$$

where $\rho_{\text {gas }}$ and $\rho_{a}\left(\right.$ in $\left.\mathrm{g} / \mathrm{cm}^{3}\right)$ are the density of the free gas phase and the adsorbed phase, respectively.

Since $\rho_{a}$ cannot be determined directly, we use the following method to calculate the density of the adsorbed phase $\left(\rho_{a}\right)$ :

$$
\begin{gathered}
\rho_{a}=\rho_{b} \exp \left[-\alpha\left(T-T_{b}\right)\right], \\
\alpha=\frac{1}{v_{a}}\left(\frac{\partial v_{a}}{\partial T}\right), \\
v_{a}=v_{b} \exp \left[\alpha\left(T-T_{b}\right)\right],
\end{gathered}
$$

where $\rho_{b}$ is the density of methane at the boiling point $\left(0.424 \mathrm{~g} / \mathrm{cm}^{3}\right) ; T_{b}$ is the boiling point of methane $(111.5 \mathrm{~K}) ; v_{b}$ is the specific mass at the boiling point (in $\mathrm{mmol} / \mathrm{g}$ ); $v_{a}$ is the specific mass of the adsorbed phase (in $\mathrm{mmol} / \mathrm{g}$ ); and $\alpha$ is the thermal expansion coefficient of the adsorbed phase (in $\mathrm{K}^{-1}$ ). In our work, $\alpha$ was determined by the empirical value of 0.0025 .

The D-A equation was applied to fit the adsorption data. The adsorption parameters $W_{0}, E$, and $n$ are optimized from the least-squares criteria. The relevant equation is expressed as

$$
W=W_{0} \exp \left\{-\left[\frac{R T}{E} \ln \left(\frac{p_{0}}{p}\right)\right]^{n}\right\},
$$

where $W$ (in $\mathrm{mmol} / \mathrm{g}$ ) is the adsorption amount of methane; $W_{0}$ (in $\mathrm{mmol} / \mathrm{g}$ ) is the saturated adsorption amount of methane; $T$ is $298.15 \mathrm{~K}, 313.15 \mathrm{~K}$, and $328.15 \mathrm{~K}$, respectively; $R$ is the gas constant $(8.314 \mathrm{~J} / \mathrm{mol} \cdot \mathrm{K}) ; E$ is the characteristic energy of the adsorption system (in $\mathrm{J} / \mathrm{mol}$ ); $p_{0}$ (in $\mathrm{MPa}$ ) refers to the quasi-saturated vapor pressure at the evaluated temperature, for the adsorption measurements are above 
the critical point of methane; and $n$ is the structural heterogeneity factor. The $p_{0}$ can be estimated as

$$
p_{0}=p_{c}\left(\frac{T}{T_{c}}\right)^{2}
$$

where the subscript $c$ refers to the critical point (for methane, $p_{c}$ is $4.59 \mathrm{MPa}$ and $T_{c}$ is $\left.190.56 \mathrm{~K}\right)$.

The prediction uncertainty is calculated from the following equation [23-25]:

$$
\delta=\sqrt{\frac{1}{N} \sum_{i=1}^{N}\left(\frac{W_{i}-W_{\mathrm{cal}, i}}{W_{i}}\right)^{2}}
$$

where $N$ is the number of data and $W_{i}$ is the data from the measured results.

Moreover, the Polanyi potential theory was employed to fit the experimental data. The relevant equations are expressed as

$$
\begin{aligned}
\varepsilon=-\int_{P}^{P s} V \mathrm{~d} P & =\int_{P}^{P s} \frac{R T}{P} \mathrm{~d} P=-R T \ln \frac{P}{P s}, \\
\omega & =\frac{W M}{22400 \rho_{a}}, \\
P_{s} & =P_{c}\left(\frac{T}{T_{c}}\right)^{k},
\end{aligned}
$$

where $\varepsilon$ is the adsorption potential (in $\mathrm{J} / \mathrm{mol}$ ); $P_{s}$ (in $\mathrm{MPa}$ ) refers to the quasi-saturated vapor pressure at the evaluated temperature, which is calculated by the Schwarz method; $\omega$ is the volume of adsorbed phase at equilibrium (in $\mathrm{cm}^{3} / \mathrm{g}$ ); $M$ is the molar mass of methane (in $\mathrm{g} / \mathrm{mol}$ ); $k$ is a parameter specific to the adsorbate-adsorbent system; and, in this study, the value of $k$ is 2.7.

The adsorption characteristic curve can be expressed as

$$
\varepsilon=A+B \omega+C \omega^{2}+D \omega^{3},
$$

where $A, B, C$, and $D$ are constants.

\subsection{Thermodynamics}

2.5.1. Heat of Adsorption. The heat release during the adsorption process is known as the heat of adsorption $\left(H_{\text {ads }}\right)$ [26]. With coal possessing a heterogeneous surface, $H_{\text {ads }}$ is essential for methane adsorption and changed greatly with the variation of surface loading $\left(W / W_{0}\right)$. The $H_{\text {ads }}$ is presented in a Clausius-Clapeyron equation, which has been used for the evaluation of $H_{\text {ads }}$ [26]. Herein, $H_{\text {ads }}$ is extracted by ClausiusClapeyron equation from the experimental adsorption data:

$$
H_{\mathrm{ads}}=\left.R T^{2}\left[\frac{\partial(\ln P)}{\partial T}\right]\right|_{W} \text {. }
$$

Invoking the D-A model (3) in (8), an explicit expression for $H_{\text {ads }}$ can be written as (9) for $T>T_{c}$ (the subscript $c$ refers to the critical point, as shown in (4)) [26]. Consider

$$
H_{\mathrm{ads}}=2 R T+E\left[\left(\ln \frac{W_{0}}{C v_{a}}\right)^{1 / n}+\frac{\alpha T}{n}\left(\ln \frac{W_{0}}{C v_{a}}\right)^{1-n / n}\right],
$$

where $W_{0}$ (in $\mathrm{mmol} / \mathrm{g}$ ) is the saturated adsorption amount of methane; $E$ is the characteristic energy of the adsorption system (in $\mathrm{J} / \mathrm{mol}$ ); $v_{a}$ is the specific mass of the adsorbed phase (in $\mathrm{mmol} / \mathrm{g}$ ); $C$ is the methane surface loading (in $\mathrm{g} / \mathrm{g}$ ); $H_{\text {ads }}$ is the heat of adsorption (in J/mol).

2.5.2. Isosteric Heat of Adsorption. Since $\beta E_{0}$ can be related to the isosteric heat of adsorption $\left(Q_{s t}\right)$ at the fractional filling $\varphi$ of $e^{-1}$ using the enthalpy of vaporization $\Delta H_{v}$ at the boiling point, $Q_{s t}$ can be expressed as $[12,13,27]$

$$
Q_{s t, \varphi=e^{-1}}=\Delta H_{v}+\beta E_{0},
$$

where $Q_{s t}$ is the isosteric heat of adsorption at the fractional filling $\varphi$ of $e^{-1}$ (in $\mathrm{J} / \mathrm{mol}$ ); $\Delta H_{v}$ is the enthalpy of vaporization of methane at the boiling point (in $\mathrm{J} / \mathrm{mol}$ ); $E_{0}$ is the characteristic adsorption energy (in $\mathrm{J} / \mathrm{mol}$ ); $\beta$ is the affinity coefficient.

2.5.3. Adsorbed Phase Specific Heat Capacity. The adsorbed phase, different from the gaseous and the liquid phase, has been assumed to be equal to the liquid phase for a long time, as well as similar to the gaseous phase. Therefore, the specific heat capacity $\left(c_{p, a}\right.$, in $\left.\mathrm{J} / \mathrm{mol} \cdot \mathrm{K}\right)$ is necessary to be determined for the adsorbed phase. To date, the $c_{p, a}$ is thermodynamically defined as the temperature derivative of the differential adsorbed phase enthalpy $\left(h_{a}\right.$, in $\left.\mathrm{J} / \mathrm{mol}\right)$ at constant surface loading $(W)[26]$; that is,

$$
c_{p, a}=\left.\left(\frac{\partial h_{a}}{\partial T}\right)\right|_{W} .
$$

Since the $H_{\text {ads }}$ can also be presented as the difference between the gaseous phase enthalpy and the adsorbed phase enthalpy by definition, the $c_{p, a}$ can be written as

$$
\begin{gathered}
H_{\mathrm{ads}}=h_{g}-h_{a}, \\
c_{p, a}=\left(\frac{\partial h_{g}}{\partial T}\right)_{P}-\left(\frac{\partial H_{\mathrm{ads}}}{\partial T}\right)_{W}=c_{p, g}-\left(\frac{\partial H_{\mathrm{ads}}}{\partial T}\right)_{W},
\end{gathered}
$$

where $h_{g}$ is the enthalpy of gaseous phase (in $J / \mathrm{mol}$ ); $h_{a}$ is the enthalpy of adsorbed phase (in $/ / \mathrm{mol}$ ); $c_{p, g}$ is the specific heat capacity of gaseous phase (in $\mathrm{J} / \mathrm{mol} \cdot \mathrm{K}$ ).

Thus, invoking the expression for $H_{\mathrm{ads}}$ from (9) in (13), the $c_{p, a}$ can be rewritten as (14) for super-critical condition

$$
c_{p, a}=c_{p, g}-2 R+\frac{\alpha^{2}(1-n)}{n^{2}} E T \ln \left(\frac{W_{0}}{C v_{a}}\right)^{(1-2 n) / n} .
$$

\section{Results and Discussion}

3.1. Textural Characterization. Coal pore morphology is mainly represented by micro- and mesopores with a wellconnected and ink-bottle shaped morphology. Most coal pores are less than $100 \mathrm{~nm}$ in diameter, making them favorable for gas adsorption but unfavorable for gas permeability. Based on the knowledge of coal nature, its pore structure is characterized by $\mathrm{N}_{2}$ adsorption/desorption isotherms. Figure 1 displayed $\mathrm{N}_{2}$ adsorption/desorption isotherms at 


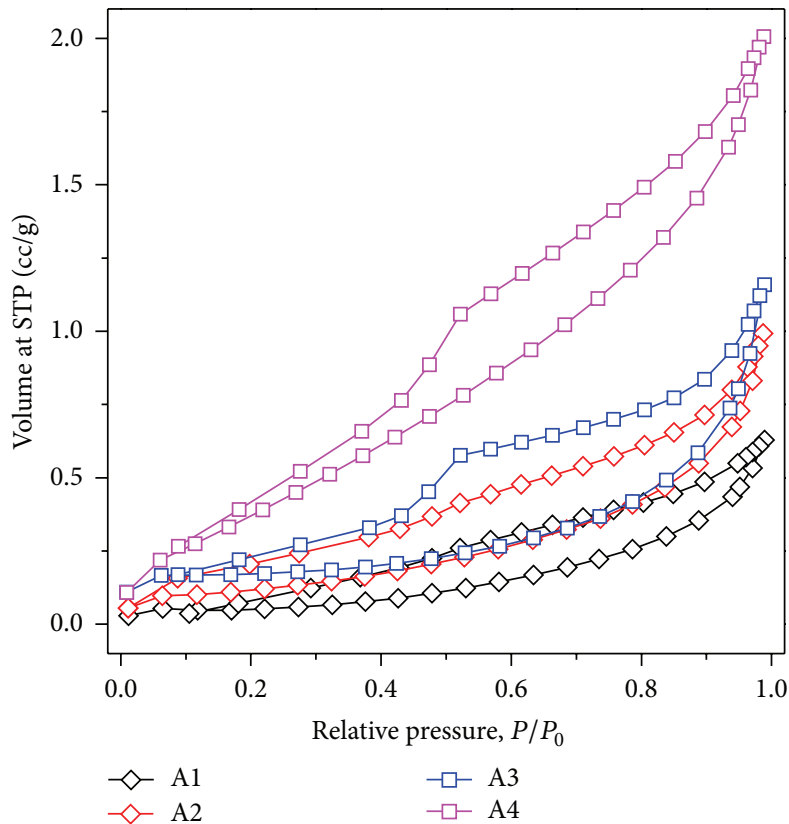

(a)

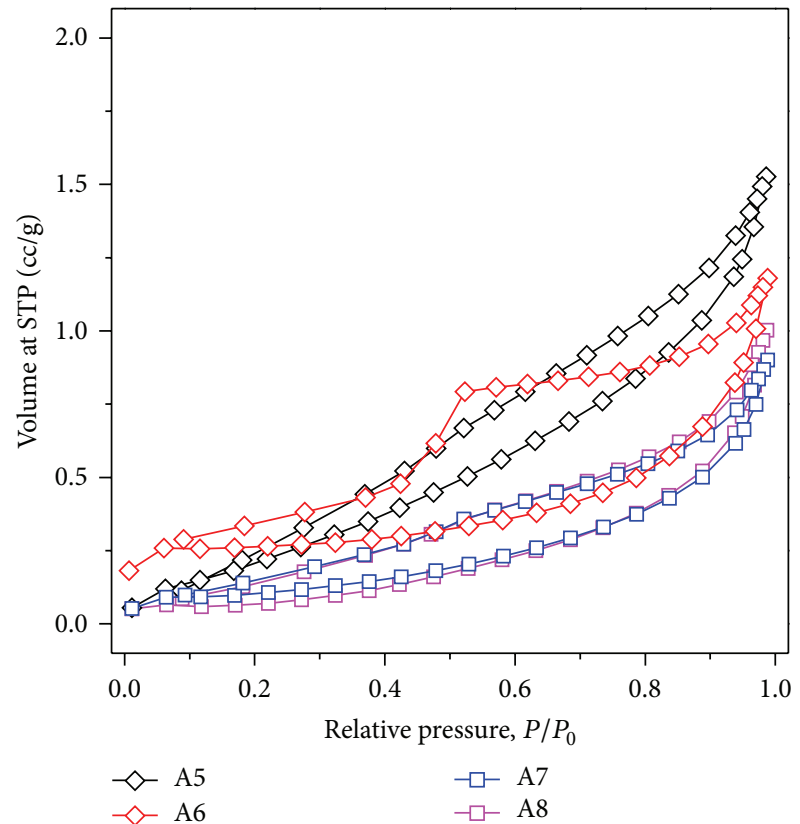

(b)

FIGURE 1: $\mathrm{N}_{2}$ adsorption/desorption isotherms (77 K) of the samples.

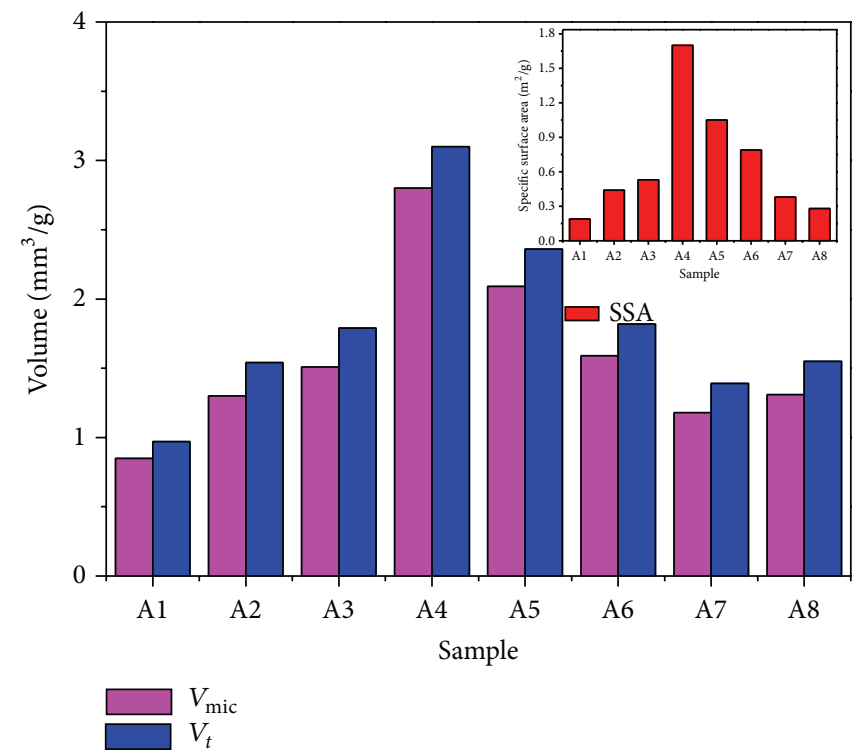

FIGURE 2: Pore structures of the samples determined by $\mathrm{N}_{2}$ adsorption/desorption isotherms. SSA was calculated by BET method, $V_{\text {mic }}$ was determined by NLDFT method, and $V_{t}$ represented the single point total pore volume at $P / P_{o} \approx 0.99$.

$77 \mathrm{~K}$ as a function of ash content. According to the BET classification, adsorption isotherms of this kind belonged to type III describing the physical adsorption process of $\mathrm{N}_{2}$. The isotherms exhibited remarkable hysteresis loops at higher relative pressures $\left(P / P_{0}>0.2\right)$. It was obvious that the isotherms of samples A4 and A5 dramatically increased on reaching a relative pressure of unity. Moreover, the adsorption volume of sample A4 was the highest among the eight samples, while the adsorption volume of A1 was the lowest.

Figure 2 presented the textural parameters for the coal samples, and the pore size distributions obtained by applying the DFT equation were shown in Figure 3. The variation of ash contents led to differences in the SSA, micropore volume, and total pore volume. Among the samples, the A1 displayed the lowest SSA and micropore volume, indicating that the development of porosity of A1 was incomplete. Compared with the others, the A4 sample had highest SSA and micropore volume, being 7.95 and 2.29 times higher than the sample A1, respectively.

Many of the physical properties of the coal show a "U-shaped" curve with a minimum or a maximum in the mid-bituminous coal rank, and the effect of ash content 


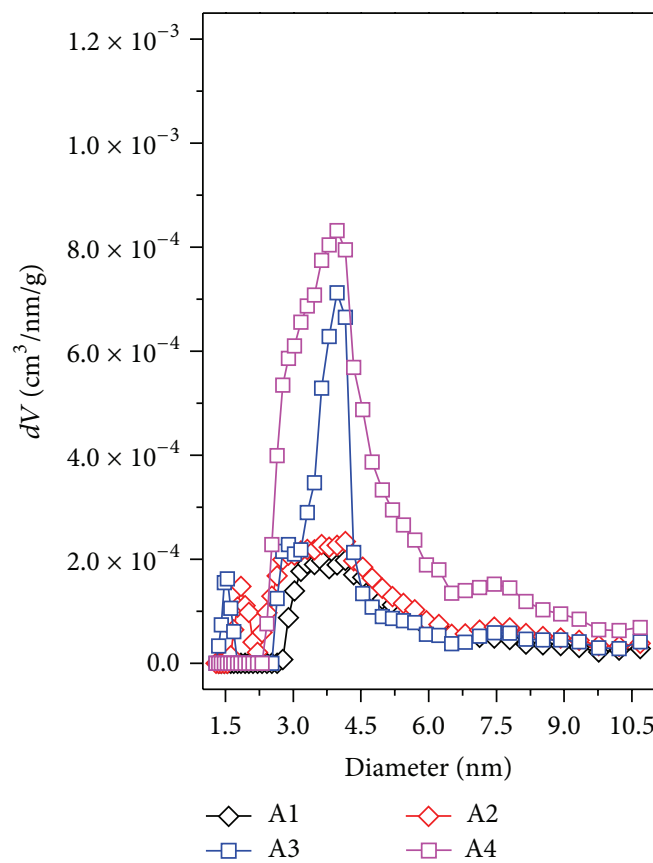

(a)

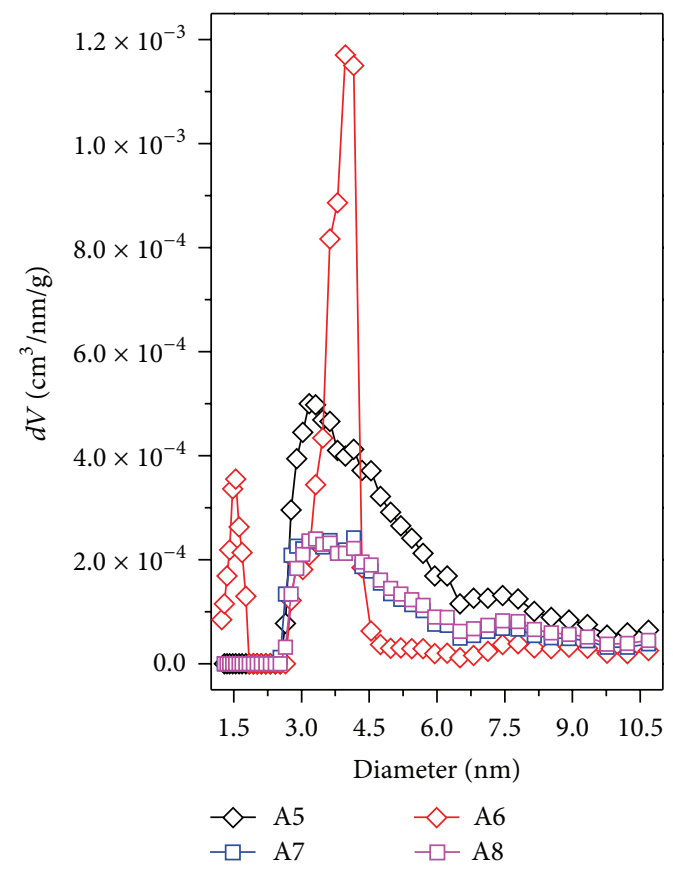

(b)

FIGURE 3: Pore size distributions obtained by applying the DFT equation.

on the pore structure was no exception. With increases in ash content range of 9.35 21.24\%, the SSA increased, going through a maximum in the ash content up to $21.24 \%$ and decreasing with further increases in ash content, as well as the micropore volume and the total pore volume. The initial decrease in porosity was related to a decrease in macro- and mesoporosity, while the subsequent increase was related to an increase in microporosity. The decreased micropore volume and total pore volume suggested that either the opened pores were closed or some micropores initially opening have been blocked by the ash.

The pore size distributions demonstrated in Figure 3 showed that the pore structures of the specimens were predominantly microporous structures $(<10 \mathrm{~nm})$ [7]. The pore volumes of the samples in Figure 3(a) were increased as a function of ash content compared with that of A1 sample. It was observed that the pore volume could be strongly influenced by ash content. As illustrated in Figure 3(b), in the case of ash content further increasing, the volume in microporous range was decreased as compared with the samples in Figure 3(a), for ash-rich coals were often more macroporous than ash-low coals in Figure 3(b). As mentioned above, the micropores were blocked by the continued increase of ash content, after being the highest total pore volume.

3.2. Methane Adsorption Isotherms. Figure 4 displayed the measured data of methane adsorption on the samples at $25^{\circ} \mathrm{C}$, $40^{\circ} \mathrm{C}$, and $55^{\circ} \mathrm{C}$ under pressures up to $4.0 \mathrm{MPa}$. The methane adsorption isotherms were Type I of IUPAC. Differences in SSA and ash content can result in variation of methane adsorption capacities. The adsorption capacities of coals increased with increasing ash content up to $21.24 \%$, passing through a maximum, and then decreased sharply with further increases in ash content. Among the samples, the sample A4 possessed the highest methane adsorption capacity and the Al sample possessed the lowest methane adsorption capacity.

The methane adsorption isotherms at lower relative pressures represent behavior dominated by Van der Waals forces, whereas the isotherms at higher relative pressures characterize actions dominated by capillary condensations. Thus, the D-A model, based on the Polanyi potential theory and applied when the adsorption process follows a pore filling mechanism, was appropriate to fit the adsorption data and provided good agreement with the experimental data. The adsorption parameters of the D-A model were described in Table 2. The parameter $n$ in D-A model describes the surface heterogeneity. It has been reported that the surface of the adsorbent is less heterogeneous when the $n$ value is approaching 3 more $(n<3)$. The value of $n$ generally changed along with the variation of ash content of the samples. The parameter $E$ in D-A model is the characteristic energy that described the strength of interaction between adsorbate and adsorbent.

The maximum adsorption capacities $\left(W_{0}\right)$ of the coal samples in the study varied from 0.45 to $0.70 \mathrm{mmol} / \mathrm{g}$. The study revealed that the ash content had different effects on the methane adsorption capacities of the coal samples. Over the ash range studied, $9.35 \%$ to $21.24 \%$, the average increase in methane adsorption capacity was $0.021 \mathrm{mmol} / \mathrm{g}$ for each $1.0 \%$ rise in ash content. For the coals with ash content range of $21.24 \% \sim 43.57 \%$, the ash content acting as a diluent strongly influenced the methane adsorption capacity (decreased about $0.0985 \mathrm{mmol} / \mathrm{g}$ for each $10 \%$ rise in ash content). 


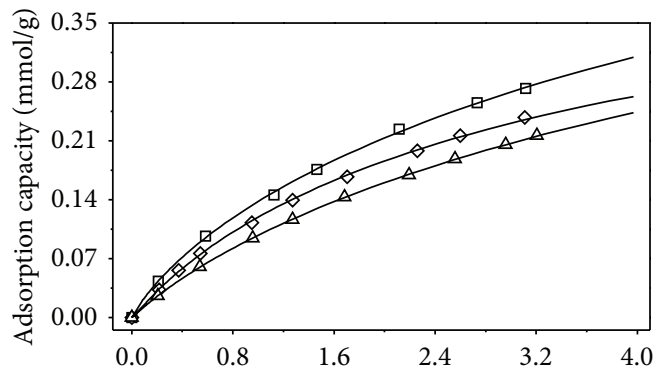

ㅁ A125

$\diamond \mathrm{A} 140$

(a)

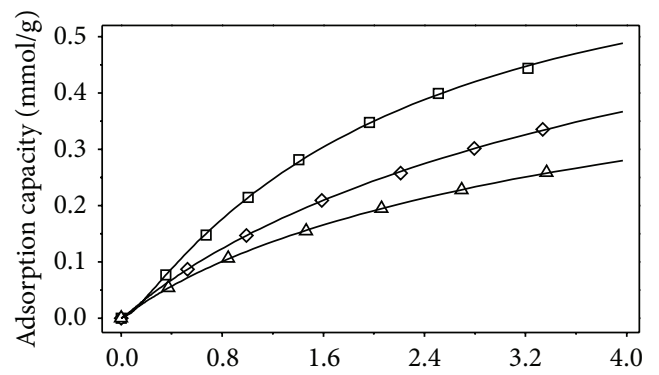

A325

$\diamond \mathrm{A} 340$

$\triangle \mathrm{A} 355$

(c)

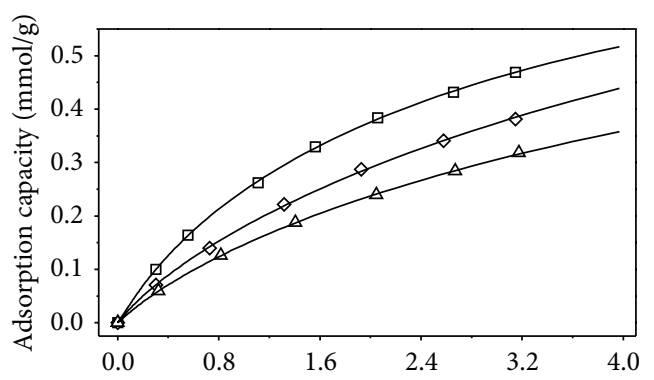

A525

$\diamond \mathrm{A} 540$

(e)

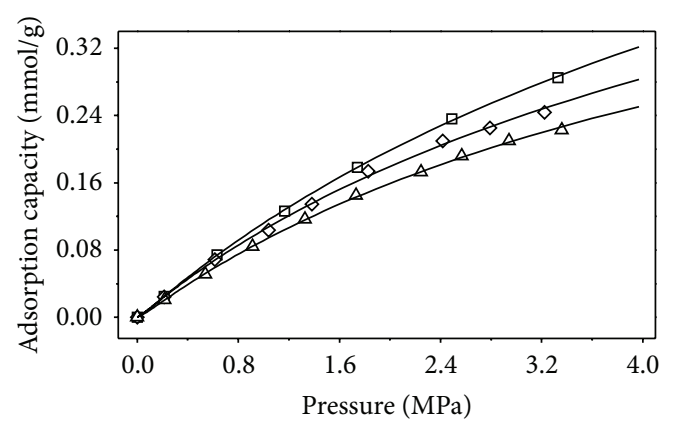

A725

$\diamond \mathrm{A} 740$

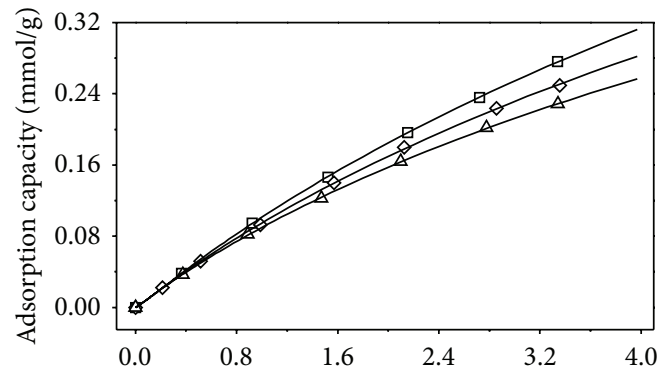

$\square \mathrm{A} 225$

$\diamond \mathrm{A} 240$

$\triangle \mathrm{A} 255$

(b)

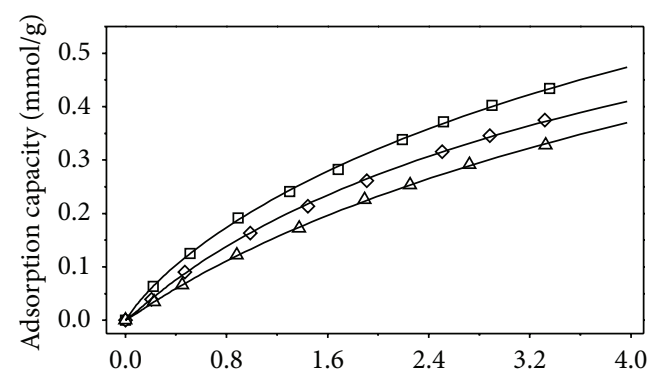

A425

$\triangle \mathrm{A} 455$

$\diamond \mathrm{A} 440$

(d)

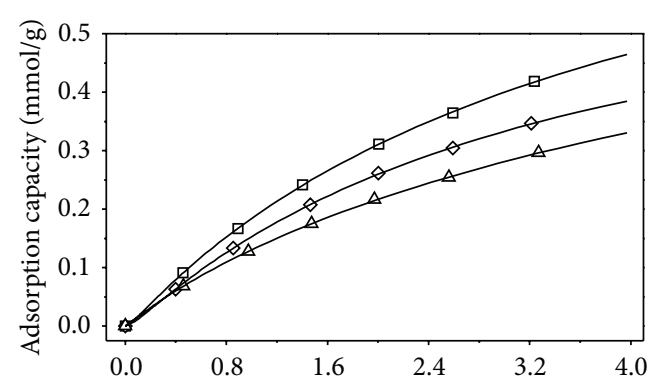

A625

$\triangle \mathrm{A} 655$

$\diamond \mathrm{A} 640$

(f)

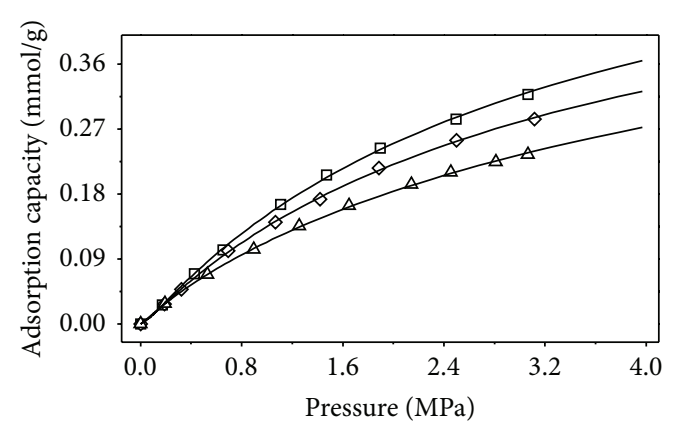

$\square \mathrm{A} 825 \quad \triangle \mathrm{A} 855$

$\diamond \mathrm{A} 840$

(h)

FIGURE 4: Methane adsorption isotherms obtained by applying the D-A model at $298 \mathrm{~K}, 313.15 \mathrm{~K}$, and $328.15 \mathrm{~K}$, respectively. (a) A1, (b) A2, (c) A3, (d) A4, (e) A5, (f) A6, (g) A7, and (h) A8; solid line, fitted by the D-A model. 
TABLE 2: Adsorption parameters of the D-A model of methane adsorption at $298 \mathrm{~K}$.

\begin{tabular}{lcccccccc}
\hline D-A model & A1 & A2 & A3 & A4 & A5 & A6 & A7 & A8 \\
\hline$W_{0}(\mathrm{mmol} / \mathrm{g})$ & 0.45 & 0.54 & 0.59 & 0.70 & 0.66 & 0.64 & 0.52 & 0.48 \\
$E(\mathrm{KJ} / \mathrm{mol})$ & 5.34 & 4.44 & 5.92 & 5.14 & 6.06 & 5.22 & 4.64 & 5.76 \\
$n$ & 1.38 & 1.31 & 1.94 & 1.37 & 1.63 & 1.60 & 1.38 & 1.68 \\
Mean relative deviation $\delta(\%)$ & 1.62 & 1.95 & 1.53 & 1.09 & 0.69 & 0.52 & 1.33 & 0.69 \\
\hline
\end{tabular}

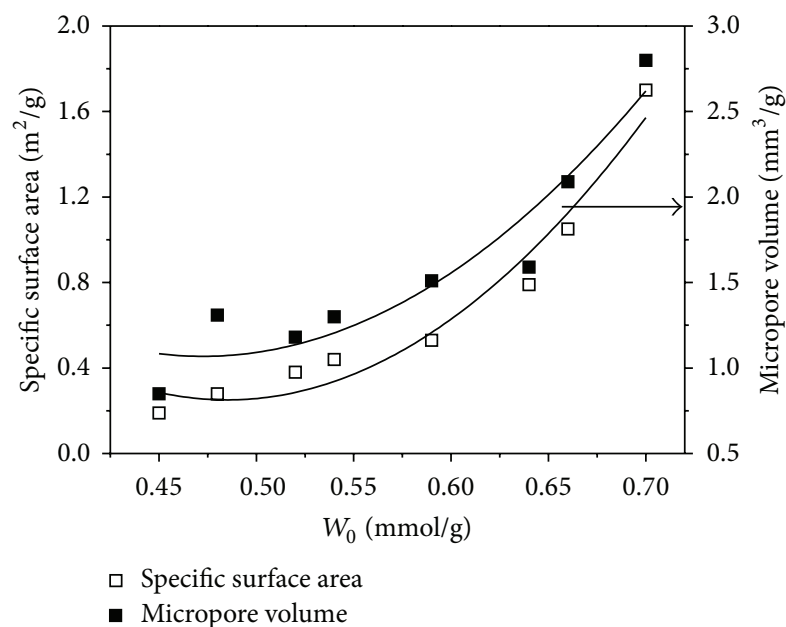

FIGURE 5: Saturated adsorption capacity $W_{0}$ related to specific surface area $(\square)$ and micropore volume $(\square)$.

The relationship between $W_{0}$ and BET specific surface area was presented in Figure 5. As a general trend, $W_{0}$ was positively related to the specific surface area of the samples. The relationship between $W_{0}$ and micropore volume was also displayed in Figure 5, and the trend was similar to that of specific surface area. Microporosity was a limiting factor for methane adsorption, so a relative increase in the amount of microporosity was translated into progressively increasing adsorption capacity of methane.

Figure 6 showed the characteristic curves of the coals with varying ash contents, and the characteristic curves were independent of temperature. If the characteristic curve for the methane-coal system is known, the adsorption behavior of methane at different temperatures could be predicted. The form of characteristic curve could influence D-A equation prediction. Using cubic polynomial form as characteristic curve could result in an abnormal prediction. Thus, a new form of characteristic curve deduced from D-A equation should be proposed in further study.

3.3. Heat of Adsorption $\left(H_{a d s}\right)$. The heat of adsorption $\left(H_{\text {ads }}\right)$ values for the samples was evaluated using $(8)$ and (9) and these were plotted in Figure 7 against the surface loading $\left(W / W_{0}\right)$. Since the heat of vaporization $\left(h_{f g}\right)$ is an increasing function of temperature above the critical point, $H_{\text {ads }}$ increased with temperature for the supercritical states as shown in Figure 7. Since the derived expression (9) requires the adsorption isotherm parameters $\left(W_{0}, E, n\right.$, and $\alpha$ ) in calculating the $H_{\mathrm{ads}}$, Table 2 presented the adsorption parameters of the D-A model of methane adsorption at $298 \mathrm{~K}$ as an example. It was observed that the $H_{\text {ads }}$ varied with the surface loading for all the samples, and the $H_{\text {ads }}$ values of samples A3, A5, and A8 were found larger compared with the others. From Figure 7, it can be also seen that the $H_{\mathrm{ads}}$ varied with coal surface loading and approached a limiting value when the adsorption process proceeded towards the saturation uptake limit. This variation of $H_{\text {ads }}$ with the surface loading was due to the surface heterogeneity of the coal. The $H_{\text {ads }}$ decreased as surfaces became less heterogeneous and the surface coverage increased.

3.4. Isosteric Heat of Adsorption. The isosteric heat of adsorption of methane was calculated from the characteristic heat of adsorption employing (10). As shown in Figure 8, the range of the values of isosteric heat of adsorption for the coals was small, between 12.6 and $14.2 \mathrm{~kJ} / \mathrm{mol}$, regardless of the ash content, and the maximum of the differences was $1.6 \mathrm{~kJ} / \mathrm{mol}$. Moreover, for a single sample at various adsorption temperatures, the differences of values of isosteric heats of adsorption of methane were located between 0.25 and $0.95 \mathrm{~kJ} / \mathrm{mol}$, much smaller than $1.6 \mathrm{~kJ} / \mathrm{mol}$. The range and magnitude of these isosteric heats of adsorption values suggested a physical adsorption mechanism rather than a chemisorption mechanism. Since the isosteric heat of adsorption should decrease as the surfaces became less heterogeneous and the surface coverage increased [26], herein, it was suggested that the changes in the isosteric heat of adsorption were due to the heterogeneity of the pore surfaces of the coals.

3.5. Adsorbed Phase Specific Heat Capacity. The adsorbed phase specific heat capacity $\left(c_{p, a}\right)$ is function of pressure, temperature, and amount of adsorbate adsorption, whereas the bulk specific heat capacity $\left(c_{p}\right)$ depends only on pressure and temperature [26]. Therefore, it is necessary to evaluate the $c_{p, a}$ values for thermodynamic analysis of any adsorbateadsorbent system, such as methane-coal system. Equation (14) was developed for this purpose.

The $c_{p, a}$ values were evaluated for methane adsorption onto the coal samples and plotted against ash content in Figure 9 for constant pressure, $P=0.1 \mathrm{MPa}$. Due to the availability of adsorption uptake data of methane-coal system, it was reasonable to determine the $c_{p, a}$ values for supercritical temperatures. The $c_{p, a}$ values were pressure and temperature dependent, and they were closer to the gaseous phase values. It was observed that the isobaric $c_{p, a}$ values were increasing with temperatures and also in the similar trend in case of all the samples. It was also observed that the $c_{p, a}$ values were dependent on the adsorption parameters and these plots 

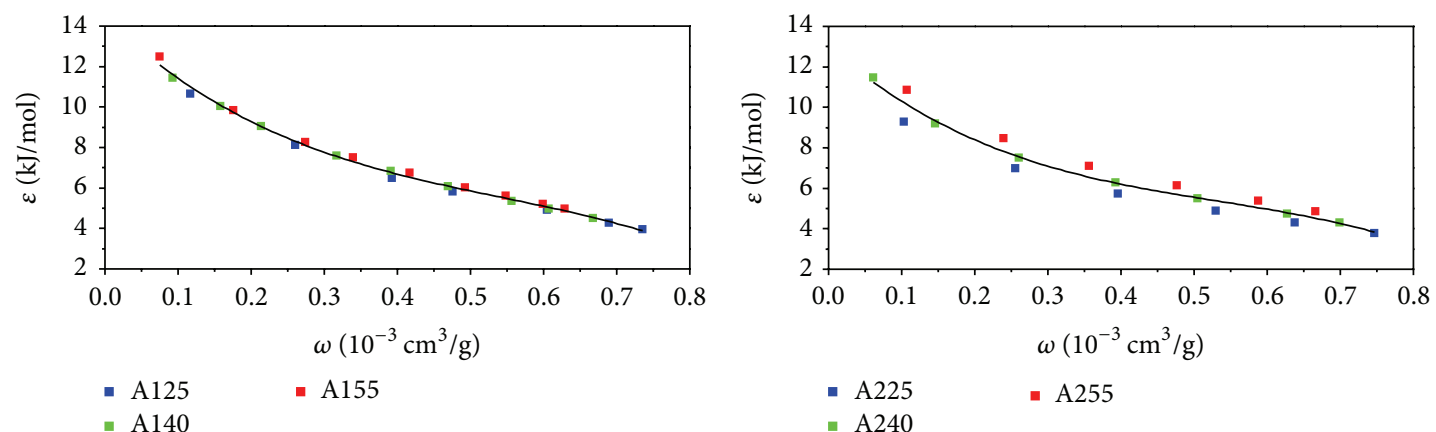

(a)
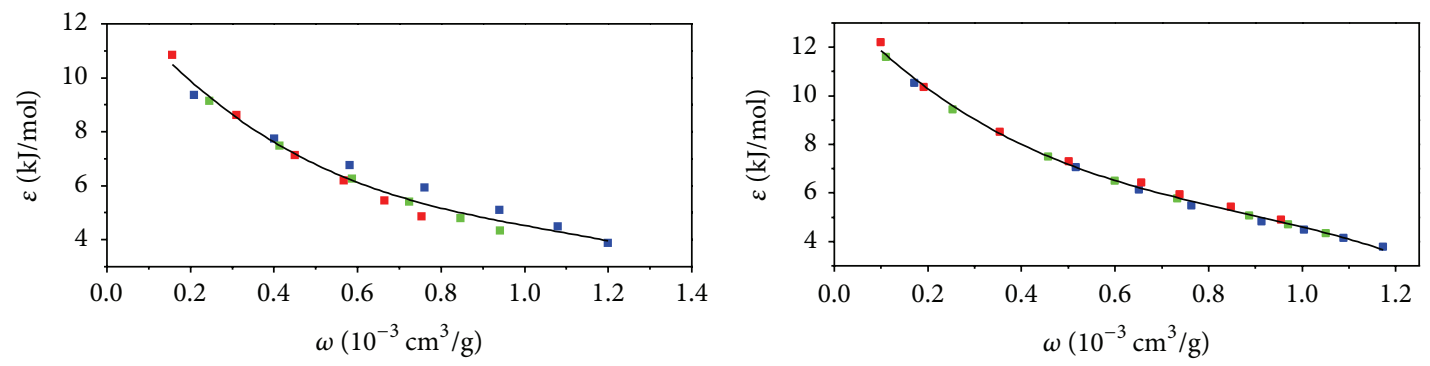

- A325

- A355

- A425

- A455

- A340

(c)

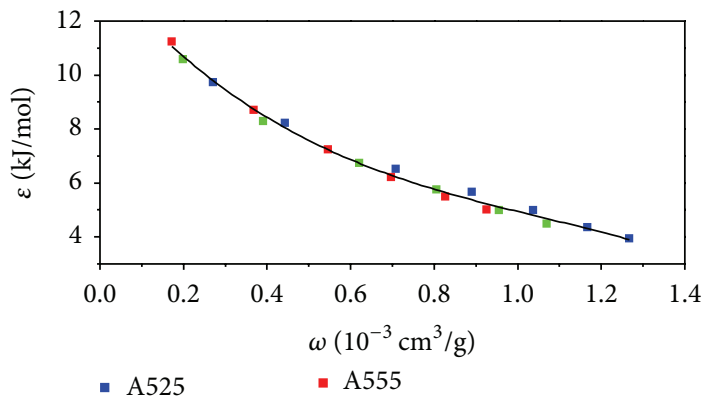

- A440

(d)

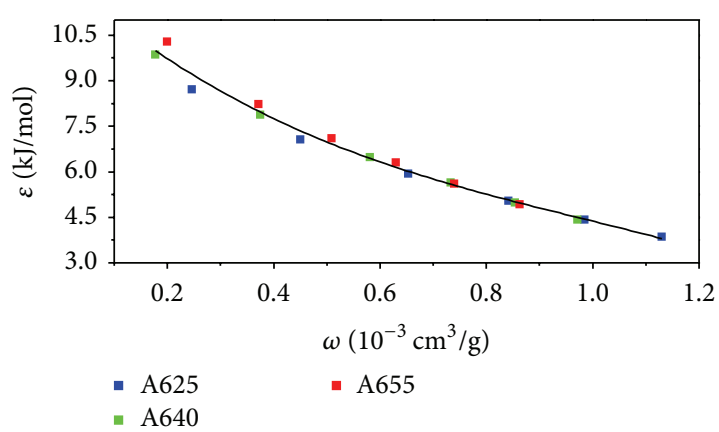

(e)

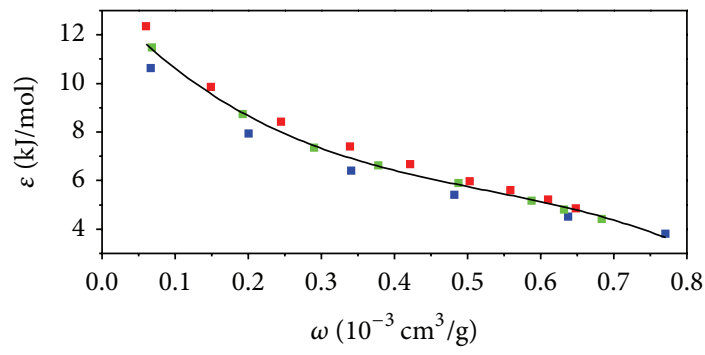

(f)

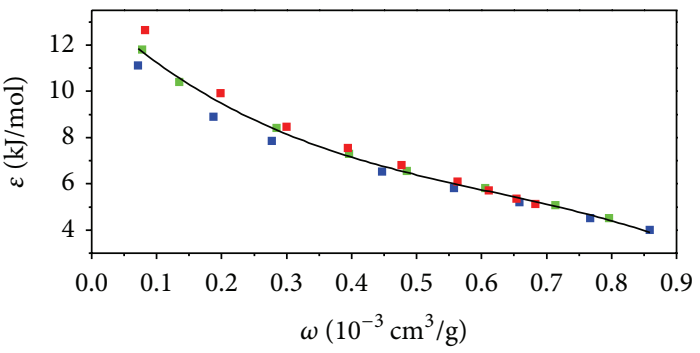

- A725

- A755

- A825

- A855

- A740

(g)

(h)

Figure 6: Characteristic curves for methane on (a) A1, (b) A2, (c) A3, (d) A4, (e) A5, (f) A6, (g) A7, and (h) A8 at 298 K, 313.15 K, and 328.15 K, respectively. 


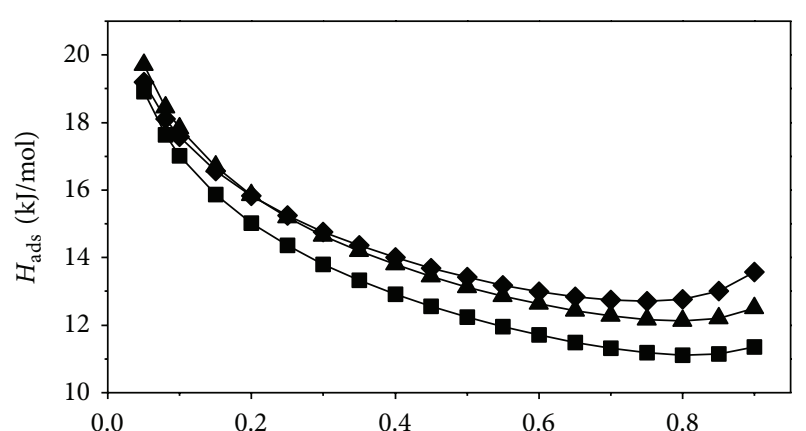

(a)

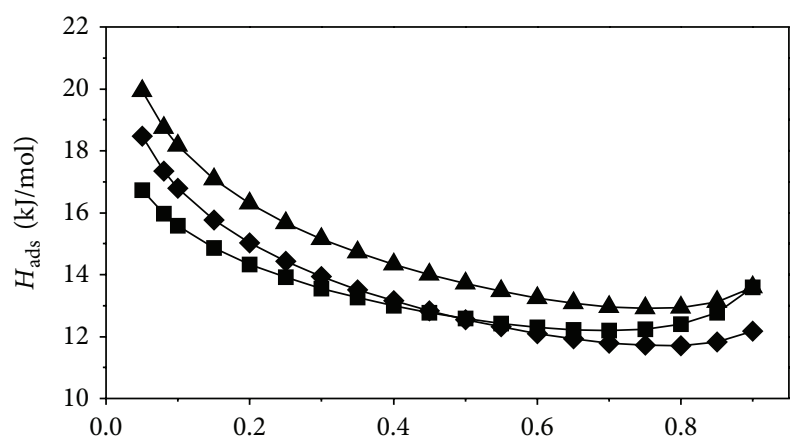

(c)

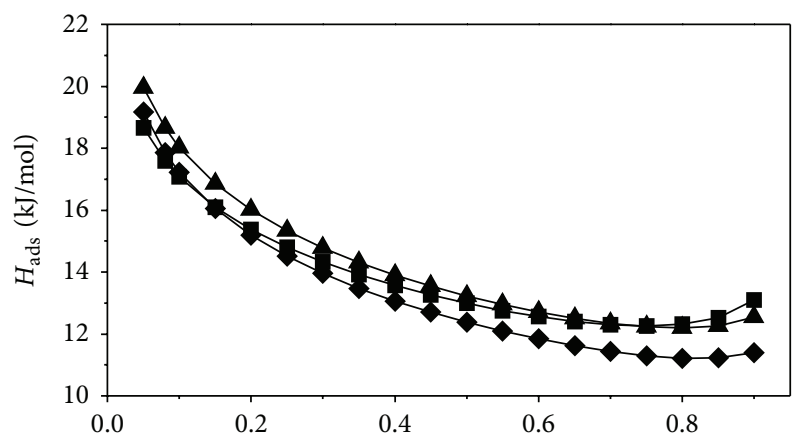

(e)

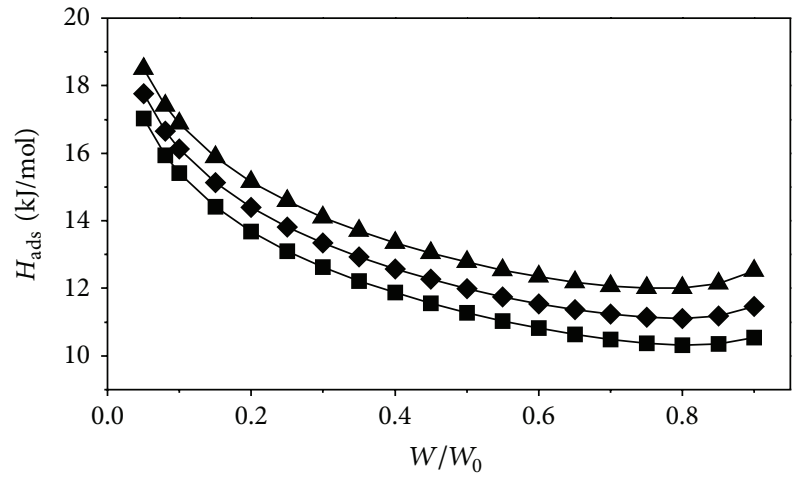

(g)

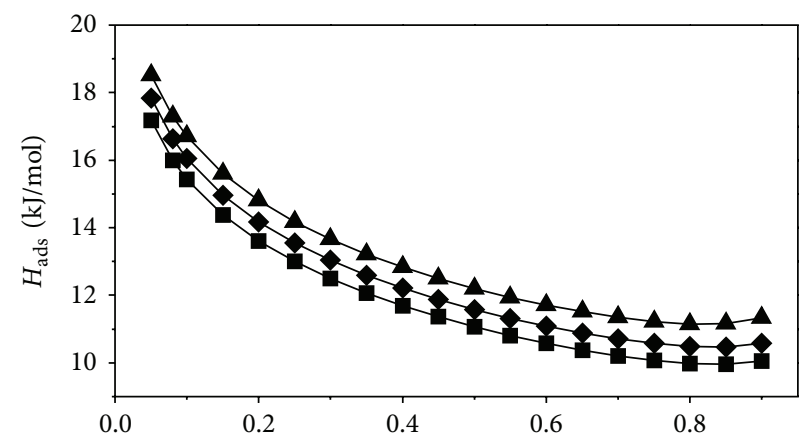

(b)

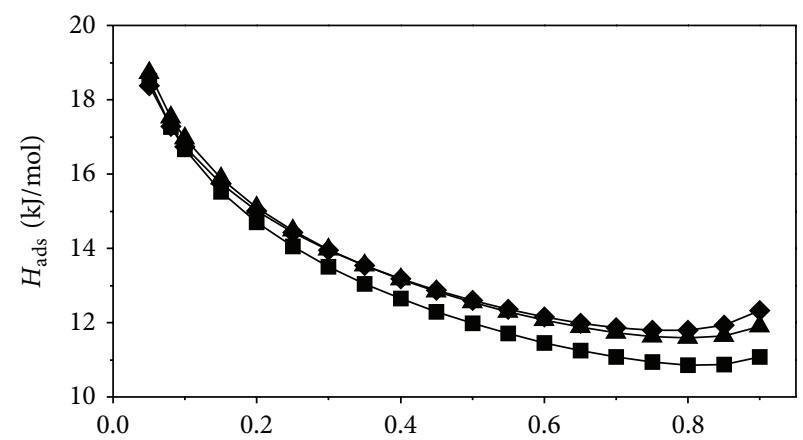

(d)

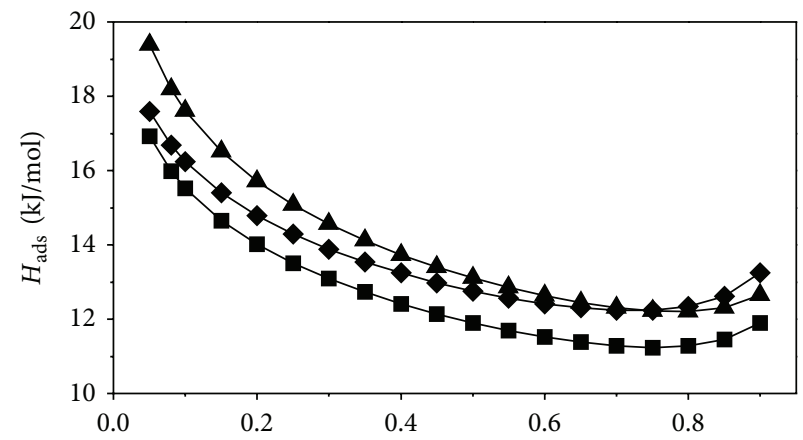

(f)

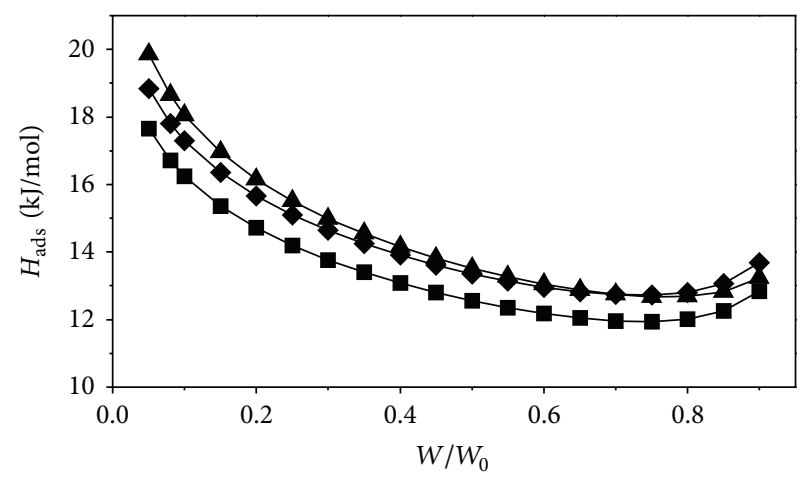

(h)

Figure 7: Heat of adsorption $\left(H_{\mathrm{ads}}\right)$ for methane/coal systems against surface loading $\left(W / W_{0}\right)$ at various temperatures. $\mathbf{m}, 298.15 \mathrm{~K} ; \boldsymbol{\downarrow}, 313.15 \mathrm{~K}$; and $\mathbf{\Lambda}, 328.15 \mathrm{~K}$. (a) A1, (b) A2, (c) A3, (d) A4, (e) A5, (f) A6, (g) A7, and (h) A8. 


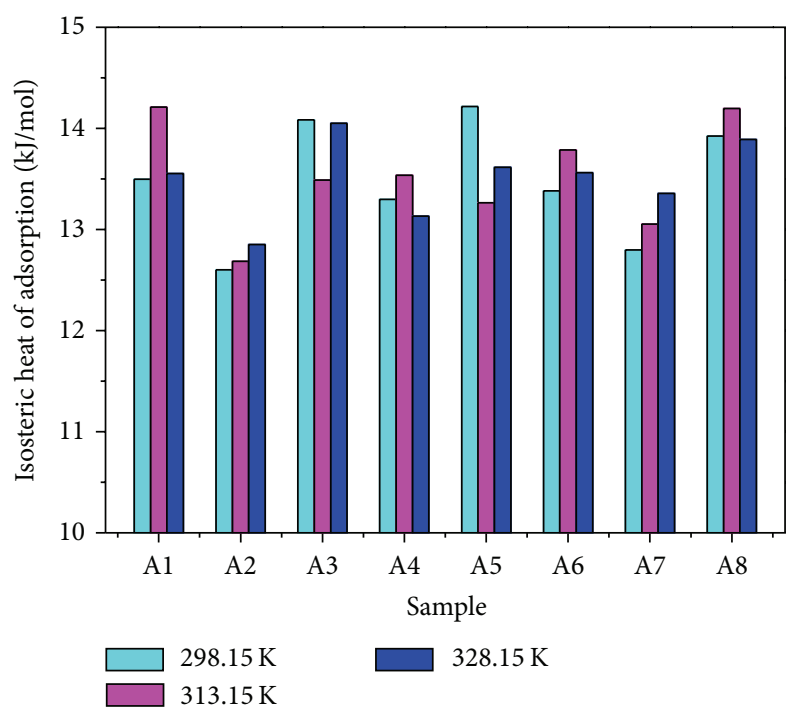

FIGURE 8: Isosteric heat of methane adsorption on the studied coals.

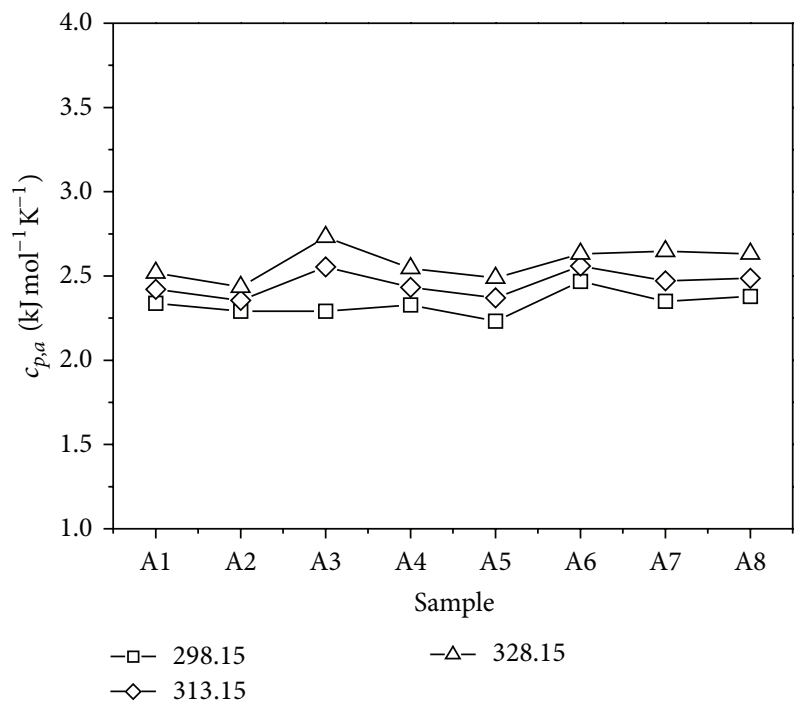

FIGURE 9: Comparison of $c_{p, a}$ values evaluated for methane adsorption onto the coals at $P=0.1 \mathrm{MPa}$.

demonstrated the dependence on the characteristics energy $(E)$ and the heterogeneity parameter $(n)$.

\section{Conclusion}

Methane adsorption behaviors on coals with varying ash contents were studied in this work. The adsorption characteristics of methane were performed at $298 \mathrm{~K}, 313 \mathrm{~K}$, and $328 \mathrm{~K}$, respectively, and pressures up to $4.0 \mathrm{MPa}$ by a volumetric method. The D-A model and the Polanyi potential theory were fitted to the experimental data, respectively, and the fitting results showed that the D-A model fitted the data well, and the characteristic curve was independent of temperature. The methane adsorption on coals involved in coordination with their physical structures and ash contents. As a result, there was a positive correlation between the saturated adsorption capacity and the SSA and micropore volume of samples. Further, ash content correlated strongly to methane adsorption capacity. Over the ash range studied, 9.35\% to $21.24 \%$, the average increase in methane adsorption capacity was $0.021 \mathrm{mmol} / \mathrm{g}$ for each $1.0 \%$ rise in ash content. For the coals with ash content range of $21.24 \% \sim 43.57 \%$, the ash content acting as a diluent strongly influenced the methane adsorption capacity (decreased about $0.0985 \mathrm{mmol} / \mathrm{g}$ for each $10 \%$ rise in ash content).

Further, this study presented the heat of adsorption, the isosteric heat of adsorption, and the adsorbed phase specific heat capacity for the adsorption of methane onto various coals. Employing the proposed thermodynamic approaches, this paper showed the thermodynamic maps of the adsorption processes of CBM for understanding the coal and gas simultaneous extraction.

\section{Conflict of Interests}

The authors declare that there is no conflict of interests regarding the publication of this paper.

\section{Acknowledgment}

This work was supported by the National Basic Research Program of China (973 Program no. 2011CB201202).

\section{References}

[1] H. Xu, D. Z. Tang, D. M. Liu et al., "Study on coalbed methane accumulation characteristics and favorable areas in the Binchang area," International Journal of Coal Geology, vol. 95, pp. 1-11, 2012.

[2] Y. Feng, C. Jiang, D. Liu, and W. Chu, "Experimental investigations on microstructure and adsorption property of heattreated coal chars," Journal of Analytical and Applied Pyrolysis, vol. 104, pp. 559-566, 2013.

[3] Y. Feng, W. Yang, D. Liu, and W. Chu, "Surface modification of bituminous coal and its effects on methane adsorption," Chinese Journal of Chemistry, vol. 31, pp. 1102-1108, 2013.

[4] H. J. Kim, Y. Shi, J. He, H.-H. Lee, and C.-H. Lee, "Adsorption characteristics of $\mathrm{CO}_{2}$ and $\mathrm{CH}_{4}$ on dry and wet coal from subcritical to supercritical conditions," Chemical Engineering Journal, vol. 171, no. 1, pp. 45-53, 2011.

[5] C. M. White, D. H. Smith, K. L. Jones et al., "Sequestration of carbon dioxide in coal with enhanced coalbed methane recovery-a review," Energy and Fuels, vol. 19, no. 3, pp. 659724, 2005.

[6] Y. Y. Feng, C. F. Jiang, D. J. Liu, and W. Chu, "Microstructure and its influence on $\mathrm{CH}_{4}$ adsorption behavior of deep coal," Chinese Physics B, vol. 23, no. 2, Article ID 028201, 2014.

[7] Y. Yao, D. Liu, D. Tang, S. Tang, and W. Huang, "Fractal characterization of adsorption-pores of coals from North China: an investigation on $\mathrm{CH}_{4}$ adsorption capacity of coals," International Journal of Coal Geology, vol. 73, no. 1, pp. 27-42, 2008 . 
[8] Y. Yao, D. Liu, D. Tang et al., "Fractal characterization of seepage-pores of coals from China: an investigation on permeability of coals," Computers and Geosciences, vol. 35, no. 6, pp. 1159-1166, 2009.

[9] C. Laxminarayana and P. J. Crosdale, "Role of coal type and rank on methane sorption characteristics of Bowen Basin, Australia coals," International Journal of Coal Geology, vol. 40, no. 4, pp. 309-325, 1999.

[10] C. Garnier, G. Finqueneisel, T. Zimny et al., "Selection of coals of different maturities for $\mathrm{CO}_{2}$ Storage by modelling of $\mathrm{CH}_{4}$ and $\mathrm{CO}_{2}$ adsorption isotherms," International Journal of Coal Geology, vol. 87, no. 2, pp. 80-86, 2011.

[11] D.-F. Zhang, Y.-J. Cui, B. Liu, S.-G. Li, W.-L. Song, and W.G. Lin, "Supercritical pure methane and $\mathrm{CO}_{2}$ adsorption on various rank coals of China: experiments and modeling," Energy and Fuels, vol. 25, no. 4, pp. 1891-1899, 2011.

[12] E. Ozdemir and K. Schroeder, "Effect of moisture on adsorption isotherms and adsorption capacities of $\mathrm{CO}_{2}$ on coals," Energy and Fuels, vol. 23, no. 5, pp. 2821-2831, 2009.

[13] S. Day, R. Sakurovs, and S. Weir, "Supercritical gas sorption on moist coals," International Journal of Coal Geology, vol. 74, no. 3-4, pp. 203-214, 2008.

[14] J. E. Fitzgerald, Z. Pan, M. Sudibandriyo, R. L. Robinson Jr., K. A. M. Gasem, and S. Reeves, "Adsorption of methane, nitrogen, carbon dioxide and their mixtures on wet Tiffany coal," Fuel, vol. 84, no. 18, pp. 2351-2363, 2005.

[15] R. Sakurovs, S. Day, S. Weir, and G. Duffy, "Temperature dependence of sorption of gases by coals and charcoals," International Journal of Coal Geology, vol. 73, no. 3-4, pp. 250258, 2008.

[16] Y. Cai, D. Liu, Y. Yao, J. Li, and Y. Qiu, “Geological controls on prediction of coalbed methane of No. 3 coal seam in Southern Qinshui Basin, North China,' International Journal of Coal Geology, vol. 88, no. 2-3, pp. 101-112, 2011.

[17] Y. Cai, D. Liu, Z. Pan, Y. Yao, J. Li, and Y. Qiu, "Pore structure and its impact on $\mathrm{CH}_{4}$ adsorption capacity and flow capability of bituminous and subbituminous coals from Northeast China," Fuel, vol. 103, pp. 258-268, 2013.

[18] M. Mastalerz, A. Drobniak, D. Strapoć, W. Solano Acosta, and J. Rupp, "Variations in pore characteristics in high volatile bituminous coals: implications for coal bed gas content," International Journal of Coal Geology, vol. 76, no. 3, pp. 205-216, 2008.

[19] Y. B. Melnichenko, L. He, R. Sakurovs et al., "Accessibility of pores in coal to methane and carbon dioxide," Fuel, vol. 91, no. 1, pp. 200-208, 2012.

[20] M. J. Lwin, "The effect of different gases on the ultrasonic response of coal," Geophysics, vol. 76, no. 5, pp. E155-E163, 2011.

[21] S. Murata, M. Hosokawa, K. Kidena, and M. Nomura, "Analysis of oxygen-functional groups in brown coals," Fuel Processing Technology, vol. 67, no. 3, pp. 231-243, 2000.

[22] S. D. Golding, I. T. Uysal, C. J. Boreham, D. Kirste, K. A. Baublys, and J. S. Esterle, "Adsorption and mineral trapping dominate $\mathrm{CO}_{2}$ storage in coal systems," in Proceedings of the 10th International Conference on Greenhouse Gas Control Technologies, vol. 4, pp. 3131-3138, September 2010.

[23] S. Hao, J. Wen, X. Yu, and W. Chu, "Effect of the surface oxygen groups on methane adsorption on coals," Applied Surface Science, vol. 264, pp. 433-442, 2013.

[24] J. Luo, Y. Liu, C. Jiang, W. Chu, W. Jie, and H. Xie, "Experimental and modeling study of methane adsorption on activated carbon derived from anthracite," Journal of Chemical and Engineering Data, vol. 56, no. 12, pp. 4919-4926, 2011.
[25] Y. Feng, W. Yang, N. Wang, W. Chu, and D. Liu, "Effect of nitrogen-containing groups on methane adsorption behaviors of carbon spheres," Journal of Analytical and Applied Pyrolysis, 2014.

[26] K. A. Rahman, A. Chakraborty, B. B. Saha, and K. C. Ng, "On thermodynamics of methane + carbonaceous materials adsorption," International Journal of Heat and Mass Transfer, vol. 55, no. 4, pp. 565-573, 2012.

[27] M. Aoshima, K. Fukasawa, and K. Kaneko, "Micropore filling of supercritical Xe in micropores of activated carbon fibers," Journal of Colloid and Interface Science, vol. 222, no. 2, pp. 179$183,2000$. 

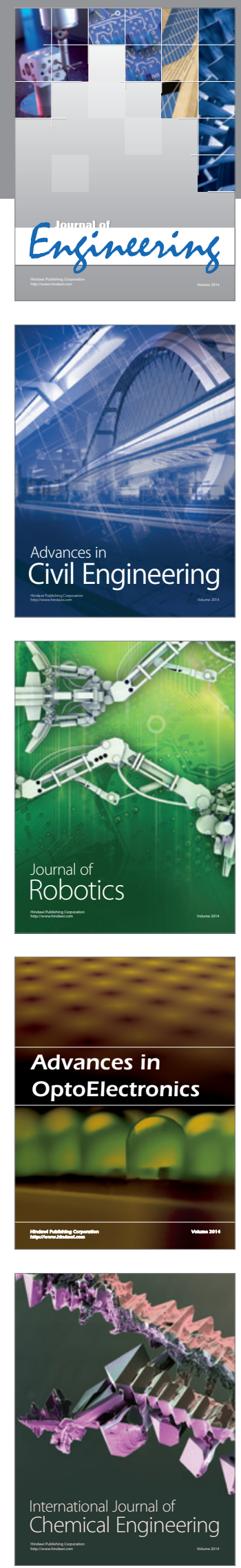

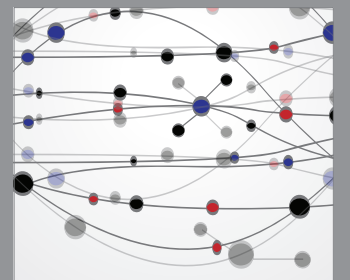

The Scientific World Journal
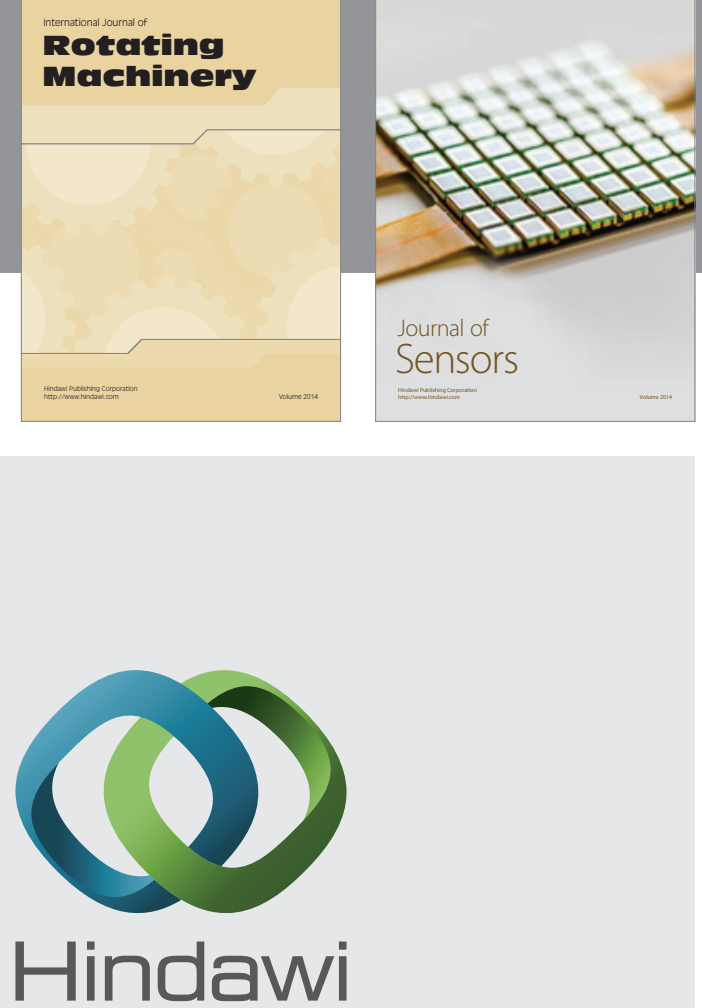

Submit your manuscripts at http://www.hindawi.com
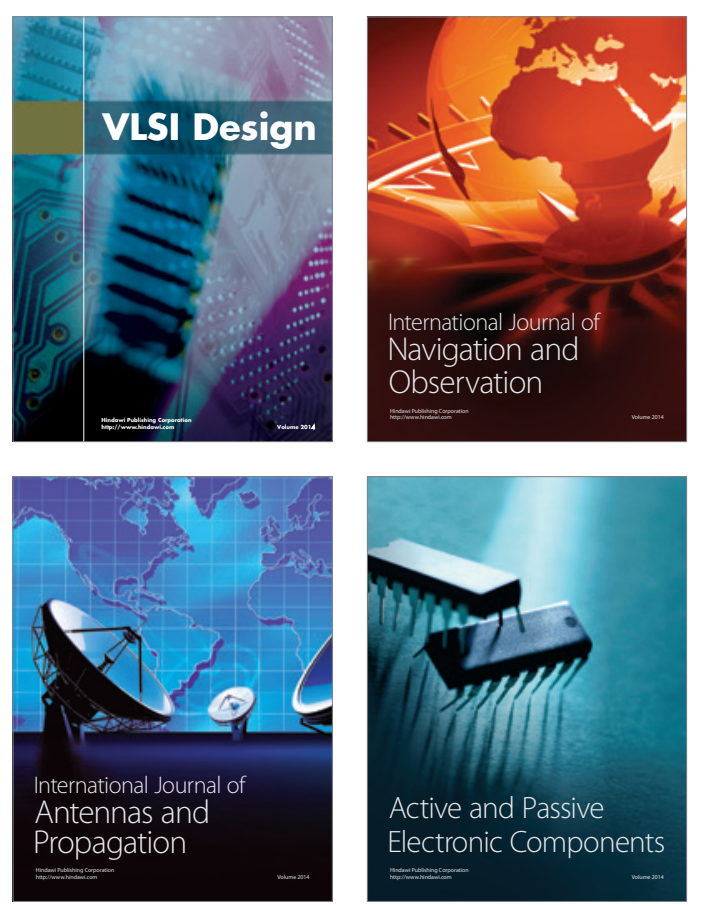
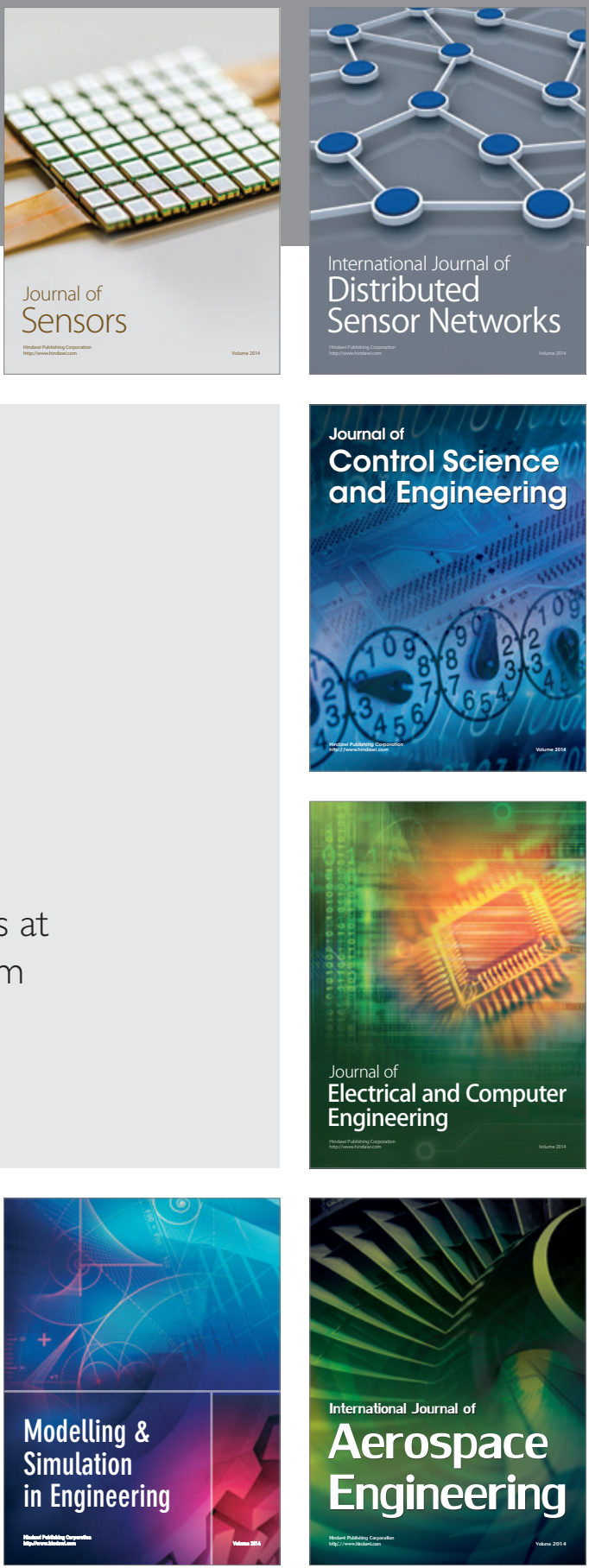

Journal of

Control Science

and Engineering
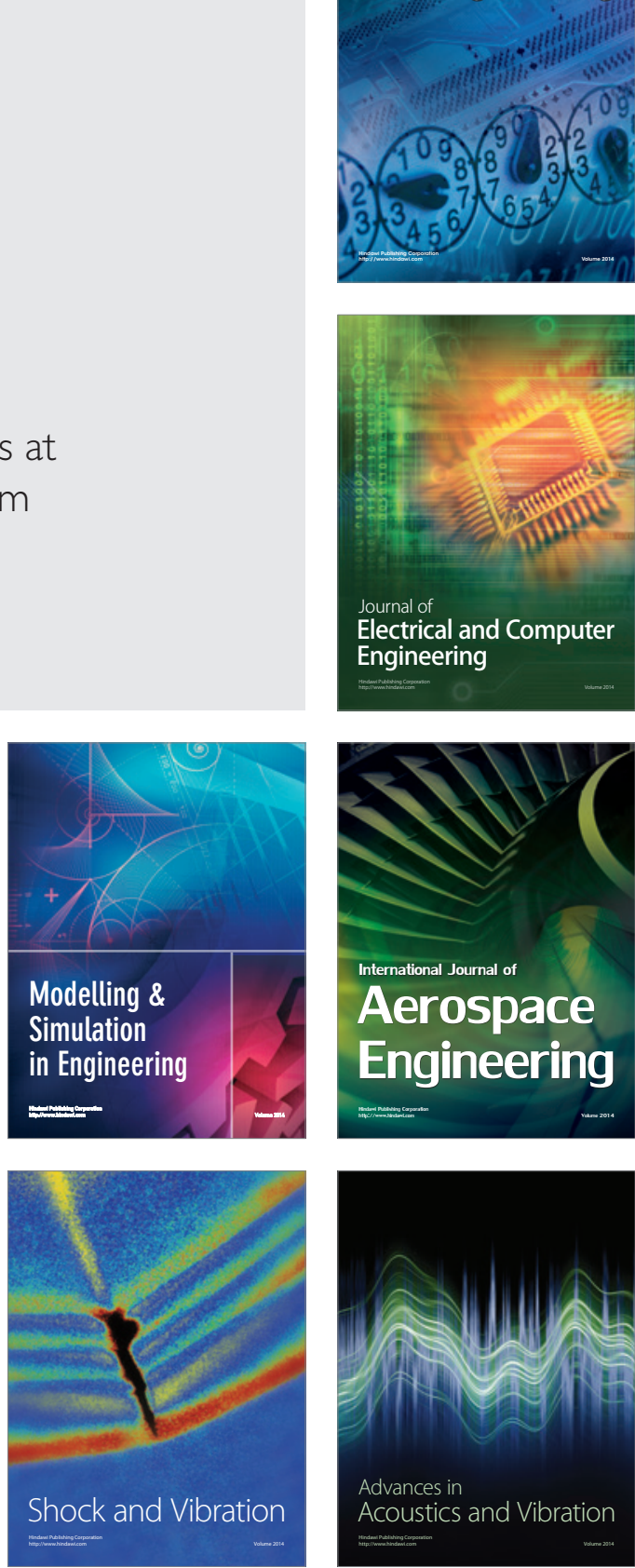